
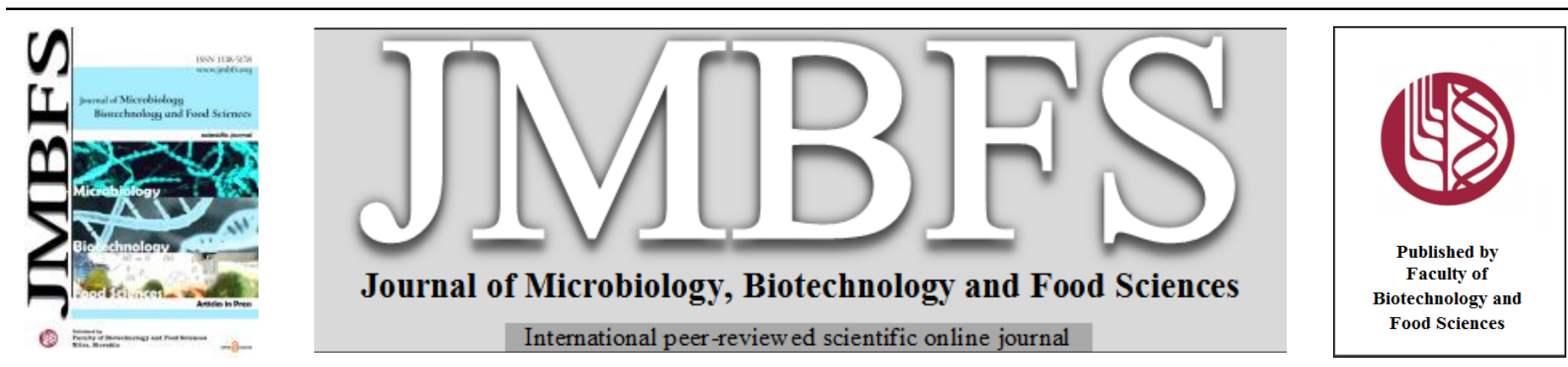

\title{
IDENTIFICATION OF Bacteroides spp. FROM DUCKS USING 16S rRNA GENE PCR ASSAY: PRELUDE TO ITS APPLICATION IN MICROBIAL SOURCE TRACKING
}

\author{
Christian Jordan O. Dela Rosa ${ }^{1,2}$, Windell L. Rivera*1 \\ Address(es): Windell L. Rivera \\ ${ }^{1}$ Pathogen-Host-Environment Interactions Research Laboratory, Institute of Biology, College of Science, University of the Philippines Diliman, Quezon City 1101, \\ Philippines. \\ ${ }^{2}$ Biology Department, College of Science, De La Salle University Manila, City of Manila 0922, Philippines.
}

*Corresponding author: wlrivera@ @sience.upd.edu.ph

https://doi.org/10.15414/jmbfs.4101

\section{ARTICLE INFO}

Received 17. 12. 2020

Revised 9. 6. 2021

Accepted 16. 6. 2021

Published 1. 12. 2021

Regular article

OPEN $\partial_{\text {ACCESS }}$

\section{ABSTRACT}

Fecal pollution monitoring using fecal indicator bacteria has many limitations. Alternatively, using 16S rRNA gene Bacteroides-based polymerase chain reaction (PCR) showed promise because Bacteroides spp. are a major part of the gut microbiota. In the Philippines, duck backyard farming waste management is unmonitored. Hence, the objective of this study was to isolate Bacteroides DNA from duck feces and to establish genetic relatedness that can be used to develop new microbial source tracking markers. Fifty (50) duck fecal samples were collected. Of the 50,20 were subjected to total DNA extraction and the remaining 30 were used for the isolation of Bacteroides. A total of 32 Bacteroides were isolated that included 6 B. nordii and 26 B. ovatus. A phylogenetic tree showing the host sources of Bacteroides generated five clusters. Four clusters came from this study, while the fifth cluster was composed of sequences from a study in Japan. This shows an intraspecies difference between Bacteroides species in the Philippines and Japan. This difference is a result of variations in the gut microbiome such as host species, diet, and geography. Results of this study will expand the present sequence database of Bacteroides from ducks that can be used in identifying sources of fecal pollution in the environment.

Keywords: Bacteroides, culture, phylogenetic analysis, polymerase chain reaction, 16S rRNA gene

\section{INTRODUCTION}

Water monitoring of fecal indicator bacteria (FIB) such as Escherichia coli and enterococci, is routinely used for determining levels of fecal pollution. However, the use of FIB has its limitations: (1) the major gut microbiota are not fecal coliforms but obligate anaerobes such as Bacteroides spp. and clostridia; (2) although $E$. coli shows specificity to fecal sources of contamination, the same cannot be said for other fecal coliforms since there are coliforms of environmental origin; (3) the presence of FIB exhibits poor correlation with the presence of pathogens in contaminated water, thus providing erroneous information; and (4) the presence of FIB does not indicate the origin of the fecal pollutant. If the origin of fecal contamination is correctly identified, more efficient mitigation plans can be put in place (Savichtcheva and Okabe, 2006; Oun et al., 2017).

In view of these limitations of FIB-based monitoring, a new method known as microbial source tracking (MST) was developed. MST is based on the principle that there are fecal microorganisms that are more strongly associated with their specific hosts and thus may be used to indicate host-specific contamination (Waso et al., 2018). MST has been used in many countries to determine and monitor the water quality of several large bodies of water (Staley et al., 2016; Symonds et al., 2017; Jardé et al., 2018; Jeong et al., 2019).

Among the MST methods developed, the most commonly used is the libraryindependent method (LIM). This method is based on the detection of hostspecific genetic biomarkers (e.g. 16S rRNA and virulence genes). LIM goes by the concept that genetic biomarker sequences are not only specific to fecal bacteria, such as Bacteroides spp., but also specific to the host species, thus allowing discrimination among suspected sources (Bernhard and Field, 2000; Rivera and Rock, 2011). The most established MST biomarkers are Bacteroides-based biomarkers. Bacteroides spp. are the most diverse group of microorganisms in the gut of most animals. They have shown to have very high level of genetic host-specificity because they tend to coevolve highly with their hosts (Bernhard and Field, 2000). Additionally, there have been several Bacteroides-based MST biomarkers developed to discriminate human fecal sources from other fecal animal sources. These Bacteroides-based MST biomarkers were designed to target specific diagnostic sequences within the Bacteroides 16S rRNA gene present in feces from various animals (Layton $\boldsymbol{e t}$ al.,
2006). Some of the widely used Bacteroides-based MST biomarkers are for humans (HF183, HuBac, BacHum, BacH), pigs (Pig-1-Bac, Pig-2-Bac), cows (BoBac, BacBov, BacCow), dogs (BacCan), geese (CGOF1-Bac, CGOF2-Bac), muskrats (MuBa01), and ducks (DuckBac) (Kobayashi et al., 2013; Koraijkic et al., 2014). Each of these MST biomarkers has shown varying degrees of sensitivity and specificity based on where the samples were collected. Hence, the need to establish MST biomarkers that would target more specific areas within the target sequence for better accuracy. The necessity to create new MST biomarkers has become even more apparent because the gut microbiome communities exhibit variations across different countries and latitudes (Yatsuneko et al., 2012; Suzuki and Worobey, 2014). For example, human MST biomarker HF183 was the best performing biomarker in the United States (California), France, Ireland, Portugal, the United Kingdom, Australia (Queensland), and Bangladesh, but it was the human MST biomarker BacHum that was found to be the best for Kenya and India. By contrast, human MST biomarker B. theta was the best performing biomarker in Darwin, Australia (Gawler et al., 2007; Ahmed et al., 2008; Jenkins et al., 2009). Hence, even places within the same geographical area (Europe [i.e. UK and Ireland] and Australia [Queensland and Darwin]) would still show differences in the performance of MST biomarkers.

Therefore, the objective of this study was to determine the genetic relatedness of Bacteroides spp. (uncultured and cultured) from ducks. The results of this study will expand the present sequence database of Bacteroides from ducks that can be used in identifying sources of fecal pollution in the environment. This database can also be used in the development of more specific duck-associated MST biomarkers that will better differentiate duck Bacteroides in the Philippines and other locations that share similar duck farming condition. This study is limited to collection of droppings from farmed ducks. Moreover, all fecal samples were collected from caged ducks, although free-ranged duck farming is also common in the Philippines. 


\section{MATERIALS AND METHODS}

\section{Fecal sample collection}

A total of 61 fecal samples were collected between February 2019 and June 2019 from the province of Laguna and Metro Manila in the Philippines. Fecal samples were collected from ducks $(n=50)$, chickens $(n=5)$, cows $(n=3)$, and dogs $(n=$ 3 ). Freshly collected feces were transported on ice to the laboratory within $24 \mathrm{~h}$. All samples were stored at $-20^{\circ} \mathrm{C}$ until use.

Duck fecal samples were collected from those found within the duck cages. Care was taken to make sure that there was no cross-contamination of fecal samples. With the assistance of farm workers, when a duck dropped feces, we were immediately informed to collect them at once. The same procedure was done in collecting chicken and cow droppings from poultry houses and cow farms, respectively. Dog droppings were collected from a local pet shop.

\section{Total DNA extraction from fecal samples}

Genomic DNA were extracted directly from 20 fecal samples of ducks, 5 from chickens, 3 from cows, and 3 from dogs using Qiagen QIAamp Stool Mini-kit (Qiagen Sciences, MD, USA) following the manufacturer's protocol. All extracted DNA were stored at $-20{ }^{\circ} \mathrm{C}$ until use.

\section{Culture and isolation of Bacteroides spp.}

The remaining 30 duck fecal samples were used for the isolation and culture of Bacteroides spp. Decimal serial dilution was done by adding $1 \mathrm{~g}$ of fecal sample to $9 \mathrm{ml}$ of normal saline water $(0.9 \% \mathrm{NaCl})$. Of the first two dilutions $\left(10^{-1}\right.$ and $\left.10^{-2}\right), 0.1 \mathrm{ml}$ aliquots were spread plated in duplicates using Bacteroides Bile Esculin (BBE) agar (Laboratories Conda S.A., Spain). Plates were incubated for 4 days at $37{ }^{\circ} \mathrm{C}$ in an anaerobic condition using the Thermo Scientific ${ }^{\mathrm{TM}}$ Anaeropack $^{\mathrm{TM}}$ anaerobic gas generator (ThermoFisher Scientific, USA). Preliminary indication of growth was observed when the brownish agar color of BBE agar turned to black. Distinct gray, circular, raised colonies were selected and re-streaked into fresh $\mathrm{BBE}$ agar for purification and incubated at $37{ }^{\circ} \mathrm{C}$ for 3 4 days in an anaerobic condition. Streaking for isolation, well-isolated colonies were sub-cultured every 3 weeks.

Extraction of DNA from pure Bacteroides cultures was done using the boiling method (Garcia et al., 2015). The resulting suspension was vortexed and placed in a dry bath at $100{ }^{\circ} \mathrm{C}$ for $15 \mathrm{~min}$. The resulting DNA extracts were kept at -20 ${ }^{\circ} \mathrm{C}$ until use.

\section{Polymerase chain reaction $(\mathrm{PCR})$}

The amplification of Bacteroides 16S rRNA gene was done using Bacteroides specific primer pairs, Bac32F (5'-AAC-GCT-AGCTAC-AGG-CTT-3') and Bac708R (5'-CAA-TCG-GAG-TTC-TTC-GTG-3') (Bernhard and Field, 2000) The $30 \mu \mathrm{L}$ PCR mixture contained 2X GoTaq Green Mastermix (Promega Corporation, Madison, WI, USA), $0.5 \mathrm{mM}$ of each primer, $3 \mu \mathrm{L}$ of DNA template and sterile nuclease-free water. The cycling conditions were as follows: $98^{\circ} \mathrm{C}$ for $2 \mathrm{~min}$, followed by 35 cycles of $95^{\circ} \mathrm{C}$ for $30 \mathrm{sec}, 56^{\circ} \mathrm{C}$ for $1 \mathrm{~min}$, and $72{ }^{\circ} \mathrm{C}$ for $1 \mathrm{~min}$ and a final extension of $72{ }^{\circ} \mathrm{C}$ for $5 \mathrm{~min}$. PCR products were separated using $1 \%(\mathrm{w} / \mathrm{v})$ agarose gel electrophoresis and visualized with staining by SYBR Safe DNA gel stain (Invitrogen, ThermoFisher Scientific, USA) under UV illumination.

\section{Sequencing and phylogenetic analyses}

PCR amplicons were sent to Macrogen, South Korea for purification and sequencing. Partial sequences (670 bp) were compared to similar sequences that are available in the National Center for Biotechnology Information (NCBI) using a BLAST Search. Sequences were aligned using MEGA X (Version 10.0.4) Additional Bacteroides sequences from other ducks were downloaded from
GenBank with accession numbers AB666138, AB666140, AB666141, $\mathrm{AB} 666152$, and $\mathrm{AB} 666154$.

Chimera sequences in the partial 16S rRNA gene sequences of Bacteroides were checked using Decipher version 2.11.03 (Wright et al., 2012) and rectified. Afterward, sequences were submitted to GenBank and were assigned the corresponding GenBank accession numbers.

Using MEGA X (Version 10.0.4), a phylogenetic tree was constructed using the Neighbor-Joining (NJ) method. Bootstrap analyses of 1000 replicates (TamuraNei) were done to approximate the confidence of the trees. The sequence of Phocaecola abscessus (EU694176), a species within the family Bacteroidaceae to which Bacteroides also belongs, was used as an outgroup.

\section{RESULTS}

\section{Isolation and molecular identification of Bacteroides spp.}

A total of 32 presumptive Bacteroides isolates were grown in culture using BBE agar at an anaerobic condition. All isolates consistently exhibited a gray, raised, and circular colonies with a change in agar color from brown to black indicative of the biochemical reaction of Bacteroides to esculin (Figure 1).

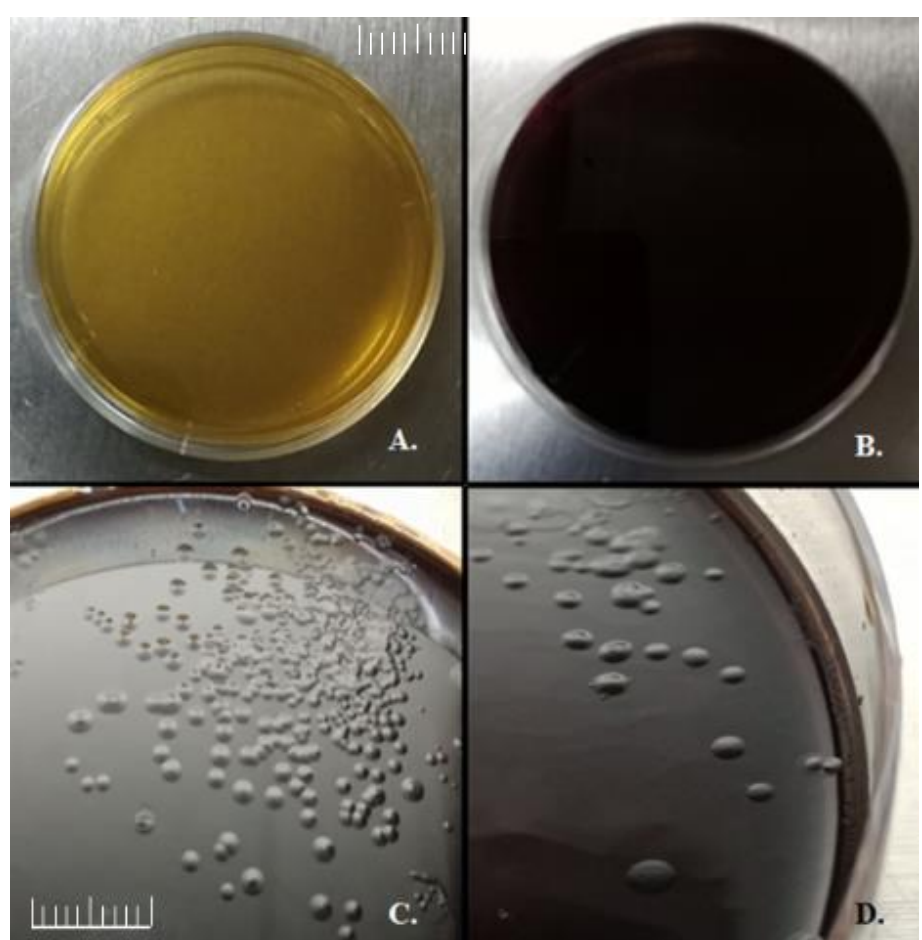

Figure 1 Bacteroides cultivation in Bacteroides Bile Esculin (BBE) Agar. (A) Uninoculated BBE Agar (underside view); (B) Inoculated BBE Agar (underside view); (C - D) Distinct Bacteroides colony growth in BBE Agar. Bar Scale: 10 $\mathrm{mm}$

On the other hand, of the 20 fecal samples collected for total DNA extraction and 16S rRNA gene amplification, only 15 samples were shown to have amplified the Bacteroides gene sequences using Bacteroides-specific primers. All the other taxonomic Orders shown in Figure 2 are taxonomic Families within the Order Bacteroidetes. Also, as shown in Figure 2, all 15 samples that were amplified have clustered with the representative species of Bacteroides in the Family Bacteroidaceae (B. nordii, B. fragilis, B. thetaiotamicron, B. finegoldii, $B$. ovatus) with high boostrap values. 


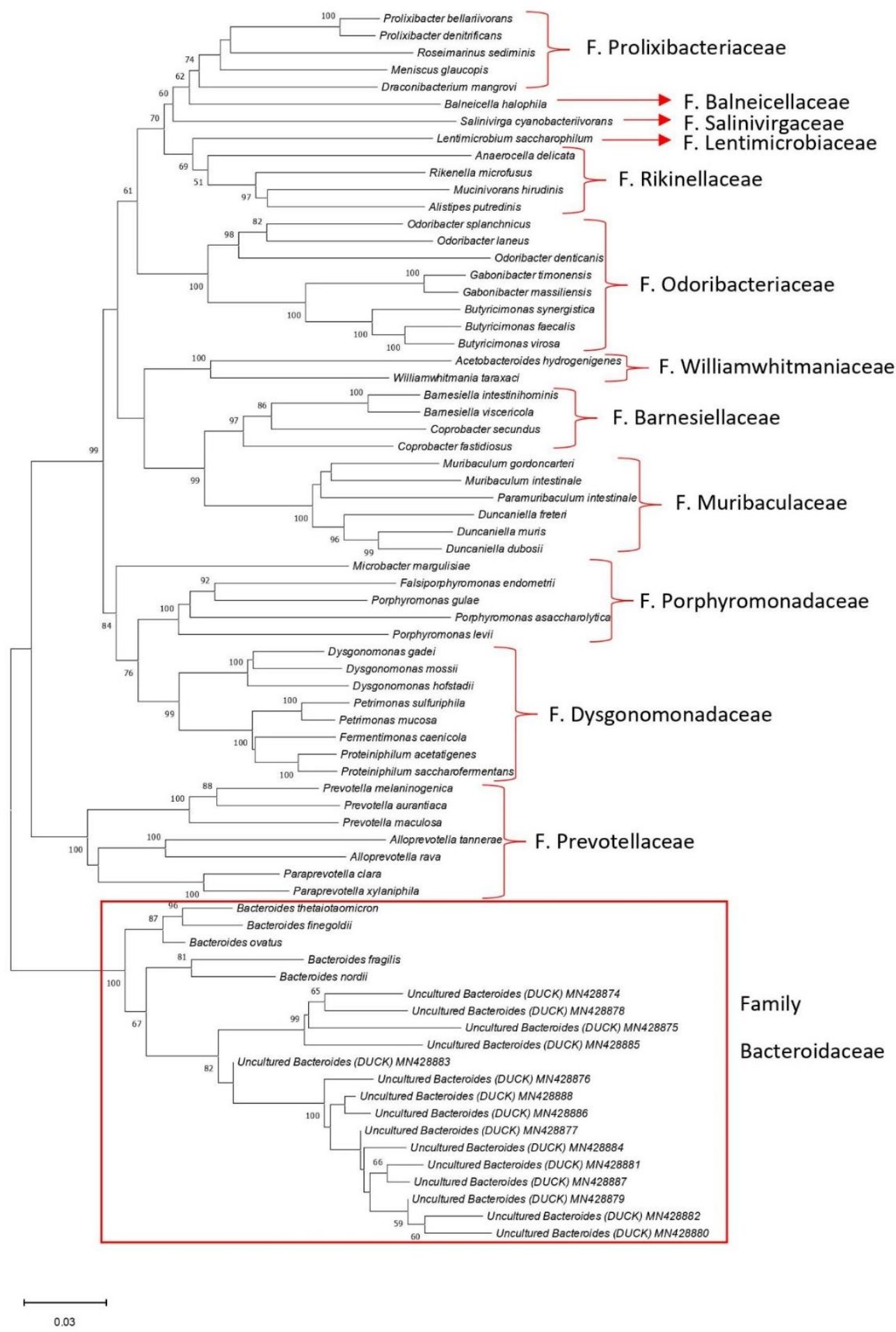

Figure 2 Phylogenetic relationships based on the partial 16S rRNA gene sequences acquired from duck fecal samples using Neighbor-Joining (NJ) method at 1000 replicates together with downloaded sequences of other families under Order Bacteroidetes. Only values $>60 \%$ are shown.

All 32 isolates were identified as Bacteroides when cross-referenced with the NCBI database. A total of 6 out of 32 Bacteroides from farmed duck feces were identified to belong to B. nordii with acceptable \% similarities of $99.35 \%-$ $99.84 \%$. This was supported by the phylogenetic tree (Figure 3) showing that the NCBI-identified B. nordii did group with the reference sequence of $B$. nordii with high bootstrap value of $99 \%$. On the other hand, 26 of the 32 isolates were identified as B. ovatus (97\%-99\%). In the constructed phylogenetic tree (Figure 3 ), all the isolates identified through NCBI as $B$. ovatus formed low bootstrap values to the reference sequence of $B$. ovatus. Thus, in such case of high NCBI percent similarity but showed low bootstrap values to the reference strain, the 26 Bacteroides isolates were simply registered and submitted to NCBI as Bacteroides spp. 


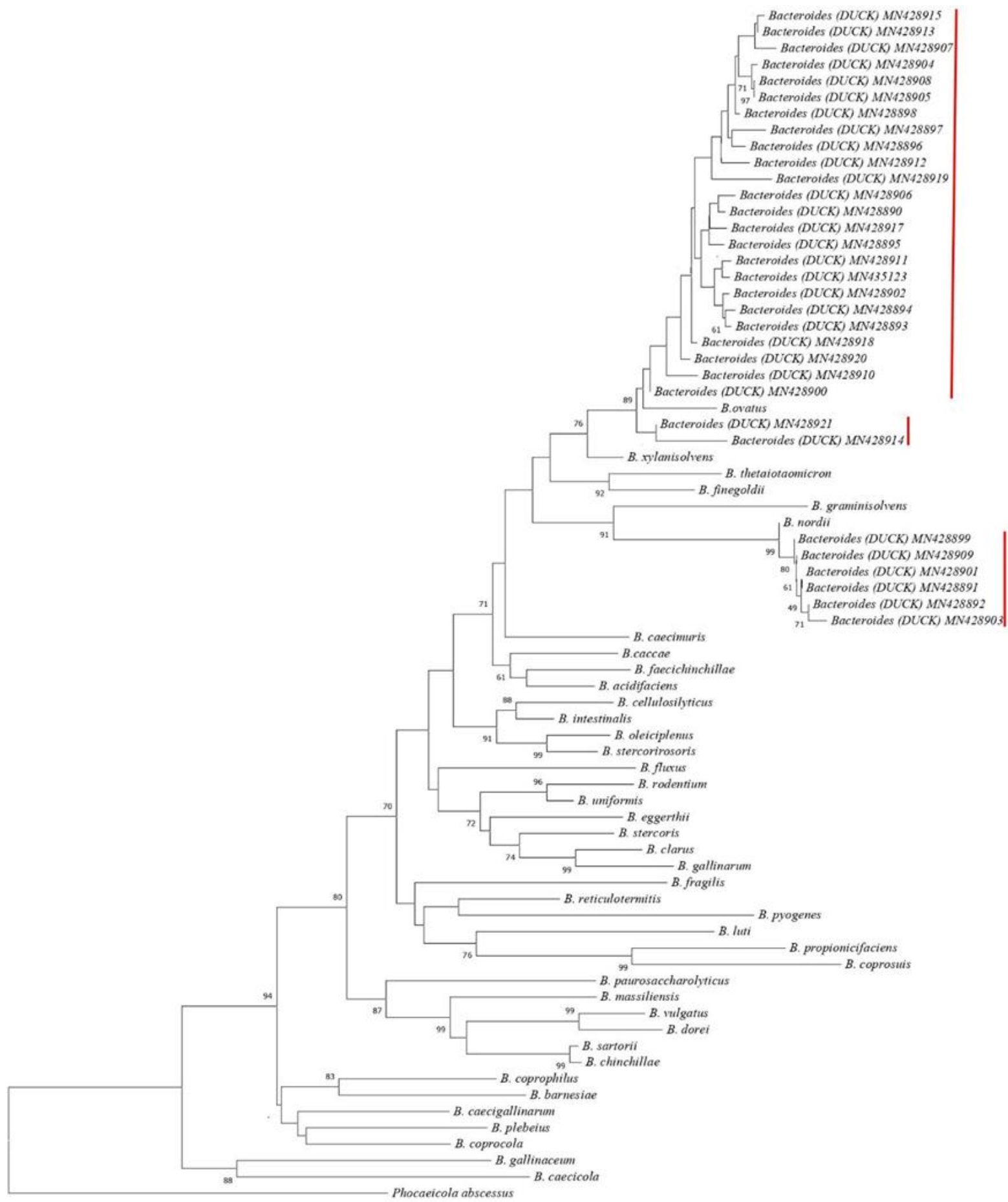

0.02

Figure 3 Phylogenetic relationships of 32 Bacteroides isolates from duck feces using 16S rRNA gene sequences with reference sequences of valid Bacteorides species using Neighbor-Joining (NJ) at 1000 replicates. Values $>60 \%$ are only shown. Phocaeicola abscessus was used as an outgroup.

\section{Duck (host)-origin phylogenetic analysis}

The 16S rRNA gene, from the extracted total DNA of duck fecal smaples and Bacteroides isolates, were amplified and sequenced. Additional 16S rRNA gene sequences were downloaded from NCBI such as those from humans, cows, pigs, chickens, goats, and fish. The phylogenetic tree shows that the sequences clustered into several clades representing Bacteroides species coming from different animal sources (Figure 4). 


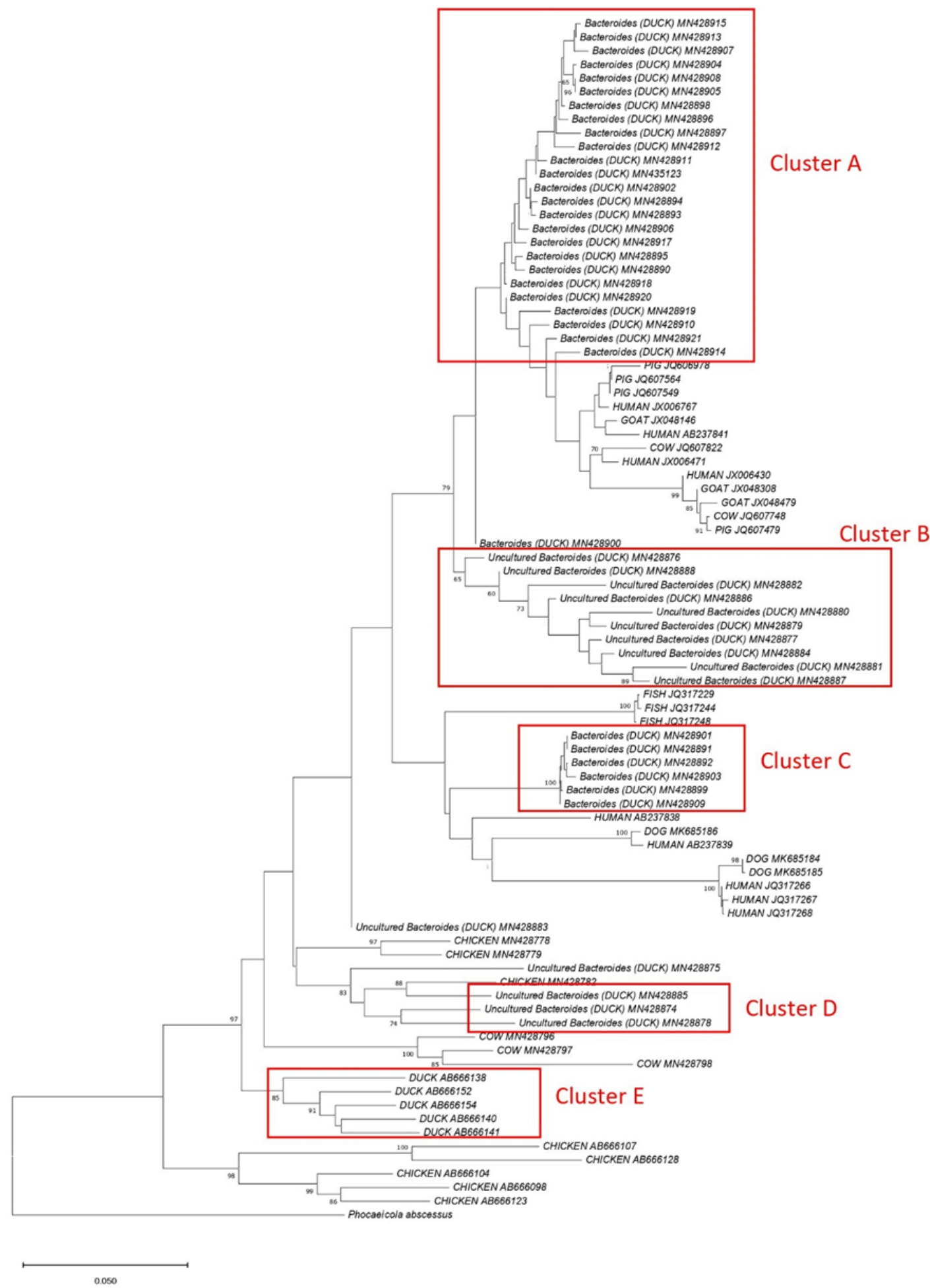

Figure 4 Phylogenetic relationships of cultured and uncultured Bacteroides sp. using 16S rRNA gene sequences from fecal samples of ducks. Phocaeicola abscessus was used as an outgroup. Values at the nodes are bootstrap values with 1000X resampling analysis. Only values $>60 \%$ are shown.

In terms of duck DNA sequences, Bacteroides grouped into 5 clusters (A, B, C, $\mathrm{D}, \mathrm{E})$. Of the 5 clusters, 4 (A-D) were samples from this study, while cluster $\mathrm{E}$ was composed of sequences taken from the study of Kobayashi $\boldsymbol{e t}$ al. (2013) that were downloaded from the GenBank. Cluster E composed of gene sequences used in developing duck-associated MST primers in Japan. Within the 4 clusters, clusters A and C came from Bacteroides cultures and clusters B and D were sequences from uncultured Bacteroides duck fecal samples. Cluster $\mathrm{C}$ has a bootstrap support value of 100 followed by cluster $\mathrm{E}$ with 85 and cluster D with 83. Cluster B has a bootstrap of 65 . Although cluster A contains most of the Bacteroides spp., it shows a bootstrap value lower than $60 \%$, hence not shown. Interestingly, all samples from the Philippines clustered and none with cluster E.

\section{DISCUSSION}

Worldwide, the duck industry has grown over the years. Similar to chickens, ducks can be consumed for their meat and eggs (Adzitey and Adzitey, 2011;
Rajput et al., 2014; Ismoyowoti and Sumarmono, 2019). In the Philippines, there are three known species of ducks. One is the native and endangered Philippine duck (locally called pato; Anas luzonica L.), while the other two are the commercially marketed non-native ducks, the Muscovy ducks (locally called itik; Cairina moschata L.) and the Mallard ducks (locally called bibe; Anas platyrhynchos L.) (Chang and Dagaas, 2004). Muscovy ducks are farmed for their meat, while Mallard ducks are grown for their eggs. The increasing market for duck meat and most especially duck eggs has generated 40.3 billion Philippine pesos accounting to $11 \%$ of the total value of Philippine agricultural production. Moreover, as of 2018, the production of duck meat and egg has risen to 31.09 thousand metric tons and 45.42 thousand metric tons, respectively. This has generated earnings of 1.68 billion pesos for duck meat and 1.99 billion pesos for duck egg. However, in contrast with other animal husbandries such as chickens, cows, and pigs, Philippine duck farming is dominated by small-scale backyard industry (70\%) (Chang et al., 2003). 
Unfortunately, the problem with such industry is the unregulated or underregulated fecal waste disposal into small bodies of water that may eventually end up in larger bodies of water allowing exposure of the general populace. Some waterfowls cater pathogens such as enterococci, E. coli, Campylobacter spp., Salmonella spp., and Cryptosporidium spp. Ducks, for example, have been shown to harbor E. coli, enterococci, Campylobacter spp., and Cryptosporidium spp. with a prevalence of $95 \%, 100 \%, 29 \%$, and $1.3 \%$, respectively (Moriarty et al., 2011). In the study of Murphy et al. (2005), pathogenic microorganisms such as Streptococcus alactolyticus/ suis/ bovis, E. coli, Staphylococcus warneri, Enterococcus cecorum, Clostrodium perfringens, Neisseria mucosa, and Campylobacter jejuni were isolated from duck feces. On the other hand, Aeromonas hydrophila, E. coli, Proteus vulgaris, Sarcina maxima, Streptobacillus moniliformis, Staphylococcus aureus, Enterococcus spp., and Streptococcus spp. were isolated from the feces of domestic ducks in Turkey (Adegunloye and Adejumo, 2014). Oocysts of Cryptosporidium were detected from duck feces and high fecal coliform levels attributed to the permanent mallard duck population in a beach in Madison, Wisconsin, USA that caused its closure (Fleming and Fraser, 2001). In the study of RamirezMartinez et al., (2018), using next generation sequencing, duck feces contained sequences from Herpesviridae, Adenoviridae, Retroviridae, and Myoviridae vira families. These studies increase our understanding of ducks as reservoir of pathogenic microorganisms and provide the basis for studying and better monitoring of the transmission of pathogens from wild animals to humans.

In this study, we detected Bacteroides through the amplification of 16S rRNA gene from total DNA extraction and culture method from fecal samples. Bacteroides are Gram negative, non-spore-forming, non-motile, and strictly anaerobic bacteria. They were targeted for isolation because they are known to be consistently present in high numbers in gut and fecal microbiota (Rivera and Rock, 2011). Due to their anaerobic nature, they have little capacity for growth outside the gut of their hosts, making them more suitable for MST since they provide a more accurate count in terms of the degree of fecal pollution (Rivera and Rock, 2011; Kabiri et al., 2016). Moreover, there is a strong correlation between the presence of Bacteroides and the presence of fecal pathogens such as E. coli, Salmonella, and Campylobacter as opposed to detecting the presence of traditional FIB that does not show a similar correlation (Walters et al., 2007; Ahmed et al., 2016). Therefore, due to the characteristics of Bacteroides spp. a majority of LIM are Bacteroides-based and are designed to target specific sequences within the 16S rRNA gene to differentiate the different sources of contamination by either conventional PCR or quantitative PCR (Hussein et al. 2014)

In the phylogenetic analysis, clusters A-D came from Philippine duck fecal samples and their respective nodes/branches formed closer groups with one another, while cluster E (Japan sequences) had a branch distinctly separate from the Philippine duck clusters. This shows an intraspecies difference between Bacteroides species in the Philippines and in Japan. This difference may depen on geographical location since clusters A-D were composed of samples collected from the Philippines, and cluster E was composed of samples from Japan. This may affect the sensitivity of MST biomarkers developed in Japan and may not be applicable to Philippine environment. Another feasible reason for this grouping is the diet of the ducks. In this study, the Philippine ducks were kept in cages and fed with the same feeds twice a day. By contrast, the DuckBac biomarker designed in Japan came from wild ducks that are free to roam and get exposed to a plethora of food that they can consume. Studies revealed that Bacteroides spp. have a high level of host-specificity because they adapt to the gut conditions of their hosts and even have the tendency to coevolve with their host species Moreover, diet produces a strong selective pressure making gut microbiomes distinct between populations (Bernhard and Field, 2000; Duncan et al., 2003; Turnbaugh et al., 2009; Garcia-Amado et al., 2018).

To our knowledge, this study is the first documentation of $B$. nordii from ducks or from an avian species since most of the sequences deposited in GenBank are of mammalian origin. Interestingly, B. nordii is consistently isolated and detected from humans. It has been shown as part of human abdominal infections, rectal/anal/perirectal abscesses (Song et al., 2004; Nagy et al., 2011). In addition, $B$. nordiii belongs to the $B$. fragilis group which has shown increasing resistance to amoxicillin, cefoxitin, clindamycin, moxifloxacin, imipinem, metronidazole, and tigecycline. There is evidence of extensive resistance gene transfer among Bacteroides spp. (Shoemaker et al., 2001; Nagy et al., 2011).

The increasing duck farming industry entails the use of more water resource since ducks are naturally adept in wet or aquatic environments. Logically, as more ducks are produced to sustain the industry so does the amount of duck feces that will be released into the environment further contributing to the aquatic fecal contamination. Unfortunately, ducks have been shown to be reservoirs of pathogenic microorganisms. Moreover, studies have shown that Bacteroides has developed extensive antibiotic resistance and can horizontally gene transfer (HGT) the genes via plasmids or conjugative elements (Shoemaker et al., 2001; Coyne et al., 2014; Huddleston, 2014). Bacteroides has already been shown to have widespread bacterial intraspecies and intrafamily HGT of antibiotic resistance genes (Coyne et al., 2014). Bacteroides poses no direct hazard when they are outside the host due to their anaerobic nature, however, within the host gut, Bacteroides can affect through HGT other bacteria or transient bacteria that can persist outside the body, to become antibiotic resistant.

Thus, this study has laid the groundwork for the need to include ducks in the monitoring of fecal contamination using the Bacteroides directly isolated from ducks. The sequences acquired in this study will serve as basis for constructing duck-specific MST biomarkers.

\section{CONCLUSIONS}

Ducks have been shown to harbor pathogens that are zoonotic, hence making them suitable for developing MST biomarkers (Moriarty et al., 2011) Bacteroides spp. are the preferred bacteria for the development of MST biomarkers because of their many advantages over the traditional FIB place (Savichtcheva and Okabe, 2006; Oun et al., 2017). Although culture-based procedures take time, they provide better phenotypic characterization of bacterial isolates. Culture-based methods in conjunction with molecular and metagenomic techniques can help in strengthening the NCBI database since bulk of Bacteroides information is generated through metagenomics. The combination of methods provides a higher confidence level in the final selection of biomarkers. Afterall, metagenomics still needs the functional verification that only culturebased methods can provide. Metagenomics provides the target while culturebased methods provide the proof (Guo et al., 2014). It is recommended that since $16 \mathrm{~S}$ rRNA gene sequences from ducks are already stored in GenBank, primer design of duck-specific MST biomarkers should be forthcoming. Future studies on antibiotic susceptibility patterns of Bacteroides from ducks can also be done. Detection of antibiotic resistance genes and Bacteroides virulence genes can also be studied since there is a gap on this field of research on Bacteroides in animals.

Acknowledgments: We thank the technical support of the Laguna Lake Development Authority (LLDA). This study was financially supported by the Philippine Council for Industry, Energy and Emerging Technology Research and Development (PCIEERD) of the Department of Science and Technology.

\section{REFERENCES}

Adegunloye DV, Adejumo FA (2014). Microbial assessment of turkey (Meleagris ocellata L.) and duck (Anas platyrhynchos L.) faeces (droppings) in Akure Metropolis. Advances in Microbiology, 4(12), 774-779. https://doi.org/10.4236/aim.2014.412085

Adzitey F, Adzitey SP (2011). Duck production: has a potential to reduce poverty among rural households in Asian communities - A review. Journal of World's Poultry Research, 1(1), 7-10.

Ahmed W, Hughes B, Harwood VJ (2016). Current status of marker genes of Bacteroides and related taxa for identifying sewage pollution in environmental waters. Water, 8(6), 231. https://doi.org/10.3390/w8060231

Ahmed W, Powell D, Goonetilleke A, Gardner T (2008). Detection and source identification of fecal pollution in non-sewered catchment by means of hostspecific molecular markers. Water Science and Technology, 58(3), 579-586. https://doi.org/10.2166/wst.2008.436

Bernhard AE, Field KG (2000). A PCR assay to discriminate human and ruminant feces on the basis of host differences in Bacteroides-Prevotella genes encoding 16S rRNA. Applied and Environmental Microbiology, 66(10), 45714574. https://doi.org/10.1128/AEM.66.10.4571-4574.2000

Chang HS, Dagaas CT (2004). The Philippine duck industry: issues and research needs. University of New England, Graduate School of Agricultural and Resource Economics and School of Economics.

Chang HS, Dagaas CT, de Castro N, Ranola R, Lambio A, Malabayuabas ML (2003). An overview of the Philippine duck industry. In: 47th Annual Conference of the Australian Agricultural and Resource Economics Society, Fremantle. pp. $1-26$.

Coyne MJ, Zitomersky NL, McGuire AM, Earl AM, Comstock LE (2014). Evidence of extensive DNA transfer between Bacteroidales species within the human gut. MBio, 5(3), 1-12. https://doi.org/10.1128/mBio.01305-14

Duncan SH, Scott KP, Ramsay AG, Harmsen HJM, Welling GW, Stewart CS Flint HJ (2003). Effects of alternative dietary substrates on competition between human colonic bacteria in an anaerobic fermentor system. Applied and Environmental Microbiology, 69(2), 1136-1142. https://doi.org/ 10.1128/AEM.69.2.1136-1142.2003

Fleming R, Fraser H (2001). The Impact of Waterfowl on Water Quality Literature Review. University of Guelph.

Garcia-Amado MA, Shin H, Sanz V, Lentino M, Martinez LM, Contreras M, Michelangeli F, Dominguez-Bello MG (2018). Comparison of gizzard and intestinal microbiota of wild neotropical birds. PLOS ONE, 13(3), e0194857. https://doi.org/10.1371/journal.pone.0194857

Garcia BCB, Dimasupil MAZ, Vital PG, Widmer KW, Rivera WL (2015). Fecal contamination in irrigation water and microbial quality of vegetable primary production in urban farms of Metro Manila, Philippines. Journal of Environmental Science and Health, Part B. Pesticides, Food Contaminants, and Agricultural Wastes, 50(10), https://doi.org/10.10s80/03601234.2015.1048107 
Gawler AH, Beecher JE, Brandāo J, Carroll NM, Falcāo L, Gourmelon M, Masterson B, Nunes B, Porter J, Rince A, Rodrigues R, Thorp M, Walters JM, Meijer WG (2007). Validation of host-specific Bacteriodales 16S rRNA genes as markers to determine the origin of faecal pollution in Atlantic Rim countries of the European Union. Water Research, 41(16), 3780-3784. https://doi.org/10.1016/j.watres.2007.01.028

Guo M, Huang K, Chen S, Qi X, He X, Cheng W-H, Luo Y, Xia K, Xu W (2014). Combination of metagenomics and culture-based methods to study the interaction between ochratoxin A and gut microbiota. Toxicological Sciences, 141(1), 314-323. https://doi.org/10.1093/toxsci/kfu128

Huddleston JR (2014). Horizontal gene transfer in the human gastrointestinal tract: potential spread of antibiotic resistance genes. Infection and Drug Resistance, 7, 167-176. https://doi.org/10.2147/IDR.S48820

Hussein KR, Waines PL, Nisr RB, Glegg G, Bradley G (2014). Development and use of Bacteroides 16S rRNA polymerase chain reaction assay for source tracking dog fecal pollution in bathing waters. Hydrology Current Research, 5(1), 1-8. https://doi.org/10.4172/2157-7587.1000163

Ismoyowati, I, Sumarmono J (2019). Duck production for food security. IOP Conference Series: Earth and Environmental Science, 372(1). https://doi.org/10.1088/1755-1315/372/1/012070

Jardé E, Jeanneau L, Harrault L, Quenot E, Solecki O, Petitjean P, Lozach S, Cheve J, Gourmelon M (2018). Application of a microbial source tracking based on bacterial and chemical markers in headwater and coastal catchments. Science of the Total Environment, 610-611, 55-63. https://doi.org/10.1016/j.scitotenv.2017.07.235

Jenkins M W, Tiwari S, Lorente M, Gichaba C M, Wuertz S (2009). Identifying human and livestock sources of fecal contamination in Kenya with host specific Bacteroidales assays. Water Research, 43(19), 4956-4966. https://doi.org/10.1016/j.watres.2009.07.028

Jeong J, Wagner K, Flores JJ, Cawthon T, Her Y, Osorio J, Yen H (2019). Linking watershed modeling and bacterial source tracking to better assess $E$. coli sources. Science of the Total Environment, 648, 164-175 https://doi.org/10.1016/j.scitotenv.2018.08.097

Kabiri L, Alum A, Rock C, Mclain JE, Abbaszadegan M (2016). A tool box strategy using Bacteroides genetic markers to differentiate human from nonhuman sources of fecal contamination in natural water. Science of the Total Environment, 572, 897-905. https://doi.org/10.1016/j.scitotenv.2016.07.188

Kobayashi A, Sano D, Hatori J, Ishii S, Okabe S (2013). Chicken- and duckassociated Bacteroides-Prevotella genetic markers for detecting feca contamination in environmental water. Environmental Biotechnology, 97(16) 7427-7437. https://doi.org/10.1007/s00253-012-4469-2

Koraijkic A, Stoeckel D, Griffith J (2014). Validation of microbial source tracking markers and detection protocols: considerations for effective interpretation. In: Yates M, Nakatsu C, Miller R, Pillai SD (editors). Manual of Environmental Microbiology, $4^{\text {th }}$ Edition. ASM Press, Washington; 2014. DC p 3.4.2-1-3.4.2-13. https://doi: 10.1128/9781555818821.ch3.4.2

Layton A, Mckay L, Williams D, Garrett V, Gentry R, Sayler G (2006) Development of Bacteroides 16S rRNA gene TaqMan-based real-time PCR assays for estimation of total, human, and bovine fecal pollution in water. Applied and Environmental Microbiology, 72(6), 4214-4224. https://doi.org/10.1128/AEM.01036-05

Moriarty EM, Karki N, Mackenzie M, Sinton LW, Wood DR, Gilpin BJ (2011) Fecal indicators and pathogens in selected New Zealand waterfowl. New Zealand Journal of Marine and Freshwater Research, 45(4), 679-688. https://doi.org/10.1080/00288330.2011.578653

Murphy J, Devane ML, Robson B, Gilpin BJ (2005). Genotypic characterization of bacteria cultured from duck feces. Journal of Applied Microbiology 99(2), 301-309. https://doi.org/10.1111/j.1365-2672.2005.02590.x

Nagy E, Urban E, Nord CE, ESCMID Study Group on Antimicrobial Resistance in Anaerobic Bacteria (2011). Antimicrobial susceptibility of Bacteroides fragilis group isolates in Europe: 20 years of experience. Clinical Microbiology and Infection, 17(3), 371-379. https://doi.org/10.1111/j.1469-0691.2010.03256.x

Oun A, Yin Z, Munir M, Xagoraraki I (2017). Microbial pollution characterization of water and sediment at two beaches in Saginaw Bay, Michigan. Journal of Great Lakes Research, 43(3), 64-72. https://doi.org/10.1016/j.jglr.2017.01.014

Rajput DS, Singh SP, Ghosh S, Nema RP (2014). Duck farming, fascinating option in India. Journal of Veterinary Science and Technology, 5(3), 3-6. https://doi.org/10.4172/2157-7579.1000181

Ramírez-Martínez LA, Loza-Rubio E, Mosqueda J, González-Garay ML, GarcíaEspinosa G (2018). Fecal virome composition of migratory wild duck species. PLoS ONE, 13(11), 1-14. https://doi.org/10.1371/journal.pone.0206970

Rivera B, Rock C (2011). Microbial source tracking: watershed characterization and source identification. Tucson, Arizona, USA: College of Agriculture and Life Sciences, University of Arizona Cooperative Extension. pp. 1-8 https://repository.arizona.edu/handle/10150/225863

Savichtcheva O, Okabe S (2006). Alternative indicators of fecal pollution: relations with pathogens and conventional indicators, current methodologies for direct pathogen monitoring and future application perspectives. Water Research, 40(13), 2463-2476. https://doi.org/10.1016/i.watres.2006.04.040
Shoemaker NB, Vlamakis H, Hayes K, Salyers AA (2001). Evidence for extensive resistance gene transfer among Bacteroides spp. and among Bacteroides and other genera in the human colon. Applied and Environmental Microbiology, 67(2), 561-568. https://doi.org/10.1128/AEM.67.2.561-568.2001 Song YL, Liu CX, McTeague M, Finegold SM (2004). "Bacteroides nordii" sp nov. and "Bacteroides salyersiae" sp. nov. isolated from clinical specimens of human intestinal origin. Journal of Clinical Microbiology, 42(12), 5565-5570. https://doi.org/10.1128/JCM.42.12.5565-5570.2004

Staley ZR, Grabuski J, Sverko E, Edge TA (2016). Comparison of microbial and chemical source tracking markers to identify fecal contamination sources in the Humber River (Toronto, Ontario, Canada) and associated stormwater outfalls Applied and Environmental Microbiology, 82(21), 6357-6366. https://doi.org/10.1128/AEM.01675-16

Suzuki TA, Worobey M (2014). Geographical variation of human gut microbial $\begin{array}{llll}\text { composition. } & \text { Biology } & \text { Letters, } & \text { 10(2), }\end{array}$ https://doi.org/10.1098/rsbl.2013.1037

Symonds EM, Young S, Verbyla ME, McQuaig-Ulrich SM, Ross E, Jimenez JA, Harwood VJ, Breitbart M. (2017). Microbial source tracking in shellfish harvesting waters in the Gulf of Nicoya, Costa Rica. Water Research, 111, 177 184. https://doi.org/10.1016/j.watres.2017.01.004

Turnbaugh PJ, Ridaura VK, Faith JJ, Rey FE, Knight R et al. (2009). The effect of diet on the human gut microbiome: a metagenomic analysis in humanized gnotobiotic mice. Science Translational Medicine, 1(6), 6ra14 https://doi.org/https://dx.doi.org/10.1126\%2Fscitranslmed.3000322

Walters SP, Gannon VPJ, Field KG (2007) Detection of Bacteroidales feca indicators and the zoonotic pathogens E. coli 0157:H7, Salmonella, and Campylobacter in river water. Environmental Science and Technology, 41(6), 1856-1862. https://doi.org/10.1021/es0620989

Waso M, Khan S, Khan W (2018). Microbial source tracking markers associated with domestic rainwater harvesting systems: correlation to indicator organisms. Environmental Research, 161, 446-455 https://doi.org/10.1016/j.envres.2017.11.043

Wright ES, Safak Yilmaz L, Noguera DR (2012). DECIPHER, a search-based approach to chimera identification for $16 \mathrm{~S}$ rRNA sequences. Applied and $\begin{array}{llll}\text { Environmental } & \text { Microbiology, 78(3), 717-725. }\end{array}$ https://doi.org/10.1128/AEM.06516-11

Yatsunenko T, Rey FE, Manary MJ, Trehan I, Dominguez-Bello MG (2012). Human gut microbiome viewed across age and geography. Nature 486(7402), 222-227. https://doi.org/10.1038/nature11053 